UCRL-ID-126246

\title{
Fundamental Studies of Matrix-Assisted Laser Desorption/Ionization, Using Time-of-Flight Mass Spectrometry to Identify Biological Molecules
}

\author{
D. Eades, D. Wruck, H. Gregg
}

November 11, 1996

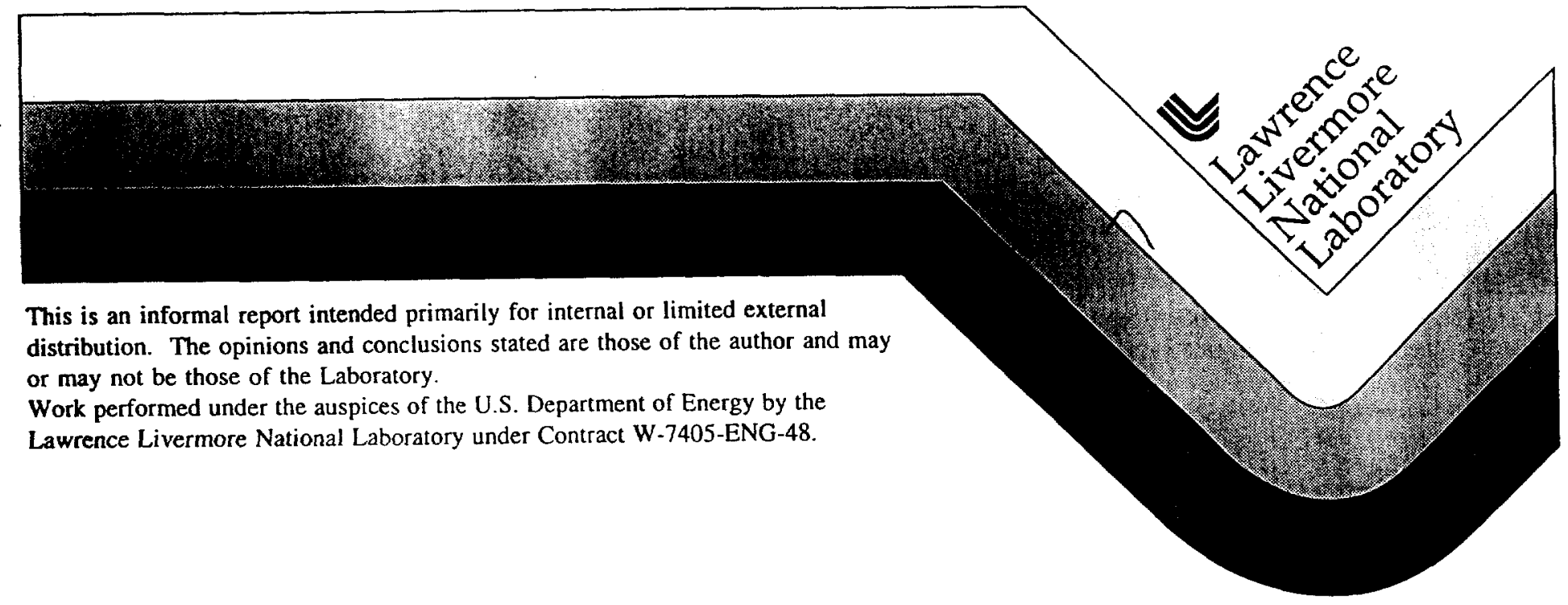




\section{DISCLAIMER}

This document was prepared as an account of work sponsored by an agency of the United States Government. Neither the United States Government nor the University of California nor any of their employees, makes any warranty, express or implied, or assumes any legal liability or responsibility for the accuracy, completeness, or usefulness of any information, apparatus, product, or process disclosed, or represents that its use would not infringe privately owned rights. Reference herein to any specific commercial product, process, or service by trade name, trademark, manufacturer, or otherwise, does not necessarily constitute or imply its endorsement, recommendation, or favoring by the United States Government or the University of California. The views and opinions of authors expressed herein do not necessarily state or reflect those of the United States Government or the University of California, and shall not be used for advertising or product endorsement purposes.

This report has been reproduced directly from the best available copy.

Available to DOE and DOE contractors from the Office of Scientific and Technical Information

P.O. Box 62, Oak Ridge, TN 37831

Prices available from (615) 576-8401, FTS 626-8401

Available to the public from the

National Technical Information Service

U.S. Department of Commerce

5285 Port Royal Rd.,

Springfield, VA 22161 


\section{Fundamental Studies of Matrix-Assisted Laser Desorption/Ionization, Using Time-of-Flight Mass Spectrometry to Identify Biological Molecules}

D. Eades, D. Wruck, H. Gregg

Matrix-assisted laser desorption/ionization (MALDI) mass spectrometry (MS) is a relatively new technique in analytical MS. This potentially revolutionary method was developed in response to the needs of the biotechnical research community who require molecular weight information on small quantities (picomole to femtomole levels) of high-mass and thermally labile macromolecules. While most other analytical MS ionization techniques cause fragmentation, decomposition, or multiple charging, MALDI efficiently places intact macromolecules into the gas phase with little fragmentation and/or rearrangement.

This project had three primary objectives: (1) establish the MALDI capability at LLNL, (2) perform fundamental studies of the MALDI process to better understand analyte-matrix interactions, and (3) apply the technique as a powerful tool for biochemical research. To meet these objectives, a retired time-of-flight (TOF) instrument was adapted for MALDI analyses, relevant parameters influencing the MALDI process were identified for further study (i.e., matrix molar absorptivity, sample crystal preparation), and collaborations were established with several research groups in the Biology and Biotechnology Research Program (BBRP) at LLNL.

The MALDI technique is accomplished by mixing the macromolecule of interest with a high-molar excess (1:100 to 1:10,000) of an organic matrix, which readily absorbs energy at the wavelength corresponding to a ultraviolet laser. ${ }^{1,2}$ The mixture is dried to form crystals, and upon laser irradiation, the matrix absorbs the majority of the energy, causing it to desorb from the surface and gently release the macromolecule into the gas phase with little or no fragmentation. Once in the gas phase, ion-molecule reactions between the excited matrix and the neutral macromolecules generate ionized analyte species which then can be focused into a MS for detection. Due to the compatibility with pulsed techniques (i.e., lasers) and an "infinite" mass range, a TOF mass analyzer typically is coupled to a MALDI source. The resulting MALDI-TOF/MS spectra consist of abundant low mass-tocharge $(\mathrm{m} / \mathrm{z})$ matrix ions and characteristic molecular weight ions, corresponding to the macromolecule of interest. Although MALDI has proven to be an efficient means of generating intact gas phase macromolecular ions, the exact mechanisms 
responsible for its success remain unclear. One current explanation is that the mechanism responsible for the MALDI processes consists of reactions occurring in both the solid and gas phase. In the solid phase, the process of sample crystal formation (and choice of organic matrix) appears to significantly influence analyteion production. ${ }^{3}$ Once desorbed and in the gas phase, ion-molecule reactions appear to be responsible for ionization, and the efficiency of the ionization appears to depend on both the matrix and analyte species. ${ }^{4}$ Due to the uncertainty in the fundamental MALDI mechanism, the process of selecting appropriate matrices for specific applications remains a trial and error approach and therefore warrants further study.

In FY95, a retired surface science instrument (a laser ionization mass analyzer, model LIMA-3 from Cambridge Mass Spectrometry LTD, Cambridge, England) was adapted for use as a MALDI-TOF/MS to study a series of synthetic peptides (from BBRP) and 10 different matrices. Interestingly, there was no clear correlation between the matrices with the highest molar absorptivity at $266 \mathrm{~nm}$ (i.e., the fourth harmonic of the Nd:YAG laser employed) and the MALDI ion signal intensities. These results suggested that factors other than the absorption of laser energy at a given wavelength contribute significantly to the successful generation of MALDI peptide spectra. Other factors which may explain the observations are the method of crystal preparation and the compatibility of the analyte and matrix in the solid phase.

The study of this peptide series also served to characterize the system for sensitivity, useful mass range, and mass resolution. Results from these studies indicated peptide sensitivities of between 50-100 picomoles, a useful mass range of up to $2000 \mathrm{Da}$, and a mass resolution of approximately 100 (i.e., $m / \Delta m=100$, where $m=$ mass-to-charge ratio of ion). However for the MALDI technique to be viable for most biological applications, increased sensitivity and mass resolution would be needed over a mass range to over $100 \mathrm{kDa}$. Therefore, the instrument was reconfigured for improved MALDI capabilities. The improvements included converting the flight path to a linear design, modifying the source to a high-voltage two-stage acceleration region with improved ion optics, inserting deflection plates to remove the abundant, interfering low-mass matrix ions, and upgrading the data acquisition and detection systems. Results from repeating the characterization studies with the peptide series on the redesigned system showed significantly higher sensitivity (5-10 picomoles), a mass resolution comparable with other linear TOF 
systems (i.e., $m / \Delta m=200$ ), and the nearly complete removal of the low-mass matrix ions. However, the mass range remained limited to less than $5000 \mathrm{Da}$.

The instrumental modifications continued into FY96. In addition to the Nd:YAG laser supplied with the original instrument, a new nitrogen laser was added which yielded a different excitation wavelength ( $337 \mathrm{~nm}$ vs $266 \mathrm{~nm}$ ), a more stable pulse-topulse power output $(3 \%$ vs $\sim 20 \%$ ), and a larger spot size $(300 \times 500 \mu \mathrm{m})$ than that from the Nd:YAG laser $(50 \mu \mathrm{m}$ diam). A precise bẹam attenuator and power meter were also added. The $\mathrm{N}_{2}$ laser was directed toward the sample stage via an alternate vacuum flange thus allowing independent use of each laser system. In a side-by-side comparison, excitation using the nitrogen laser yielded better ionization efficiency for the various combinations of matrices and peptides investigated. Figure 1 is a schematic of the redesigned instrument.

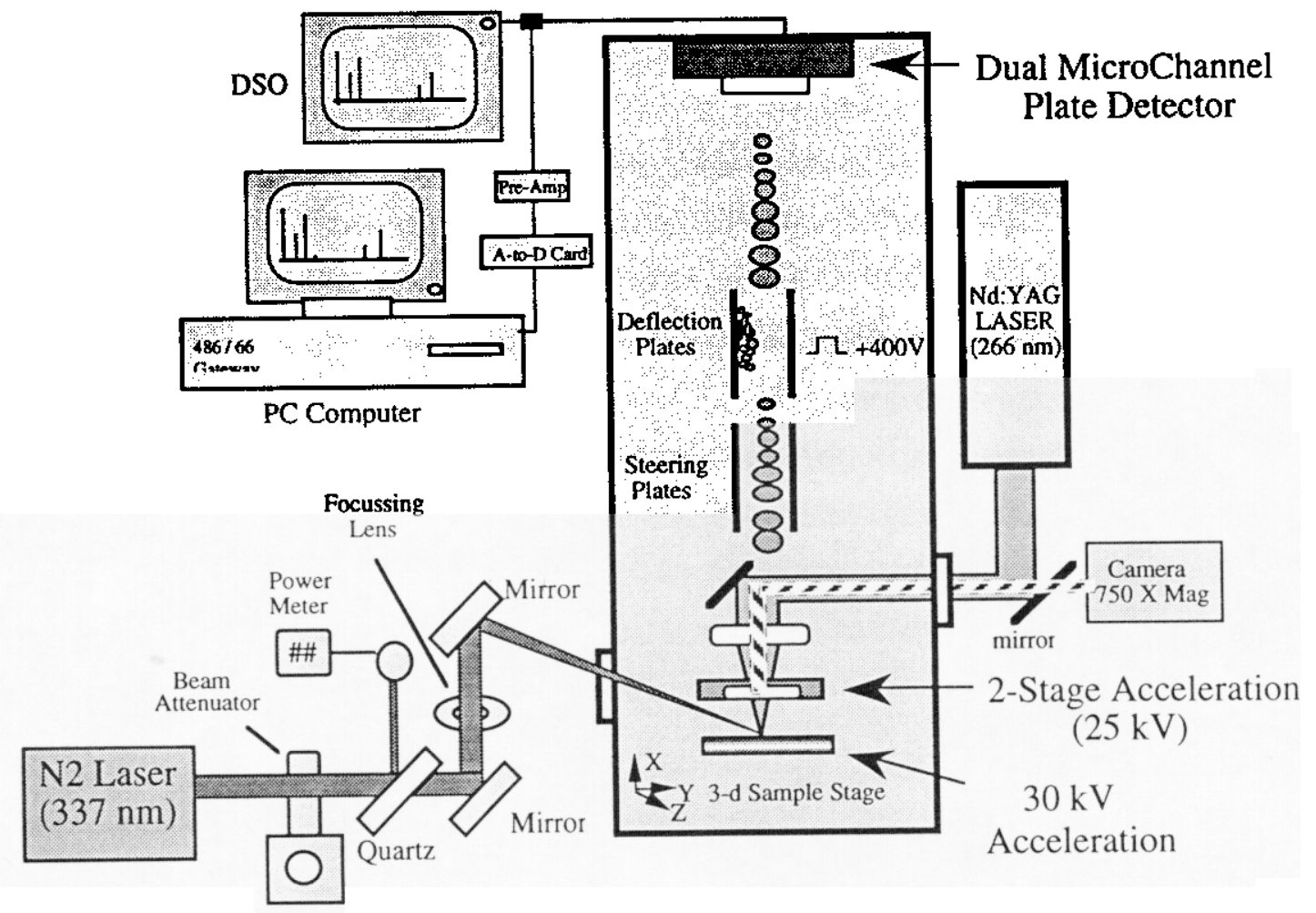

Figure 1. Current MALDI-TOF/MS system schematic.

Matrix materials (e.g., nicotinic acid, vanillic acid, sinapic acid, and gentisic acid) as well as a number of sample preparation techniques were re-evaluated. The sample preparation techniques investigated included deposition from water:acetonitrile solutions on unheated or heated sample holders, and fast deposition of the matrix from acetone followed by deposition of the analyte from a drop of aqueous solution placed on top of the matrix. For the peptide and protein 
samples examined, the highest ion currents were observed using sinapic acid as the matrix, the nitrogen laser, and the preparation technique where the sample was deposited onto an unheated sample holder from water:acetonitrile solution. The mass spectra presented here are positive ion spectra recorded with $15 \mathrm{kV}$ accelerating voltage ( $10 \mathrm{kV}$ on the "extraction" lens). Mass calibration was made using the equation $(\mathrm{m} / \mathrm{z})^{1 / 2}=\mathrm{At}+\mathrm{B}$, where $\mathrm{A}$ and $\mathrm{B}$ were determined by known low-mass ions in the matrix $\left[{ }^{23} \mathrm{Na}^{+},{ }^{39} \mathrm{~K}^{+},(\mathrm{M}-\mathrm{OH})^{+}\right.$at $207,(\mathrm{M}+\mathrm{H})^{+}$at 225 , and $(\mathrm{M}+\mathrm{Na})^{+}$at 247 , where $M=224.2$, the molecular weight of sinapic acid]. In addition, a small amount of gramicidin $S$ was added to the protein samples to give an additional calibration point at $\mathrm{m} / \mathrm{z}=1165\left[(\text { gramicidin } \mathrm{S}+\mathrm{Na})^{+}\right]$. This calibration procedure extrapolates from low-mass calibrant ions to high-mass analyte ions, and the procedure typically results in a mass assignment error of $\pm 0.1 \%$. Higher accuracy, on the order of $\pm 0.01 \%$, can be obtained by adding an internal calibrant with a mass comparable to the analyte mass. 5

Figure 2 shows a mass spectrum obtained for cytochrome c (sum of 25 laser pulses, no smoothing). The molecular weight of cytochrome $c$ is 12,327 , the mass resolution is about 200, and matrix ion adducts are seen as shoulders on the main peaks. Figure 3 is a mass spectrum obtained for bovine trypsin (sum of 80 laser pulses, no smoothing). The molecular weight of trypsin is 23,311 . The shoulder at $24,500$ may correspond to (trypsin + gramicidin $\mathrm{S}+\mathrm{Na})^{+}$. The mass resolution for the shown peaks is 40 to 45 , but the resolution of the gramicidin $S$ calibrant peak was about 200 for this sample. The low resolution at high $\mathrm{m} / \mathrm{z}$ values may arise from the formation of a large number of unresolved matrix ion adducts by the protein molecules; even with matrix ion deflection, the sample produced a large ion signal at low $\mathrm{m} / \mathrm{z}$ values.

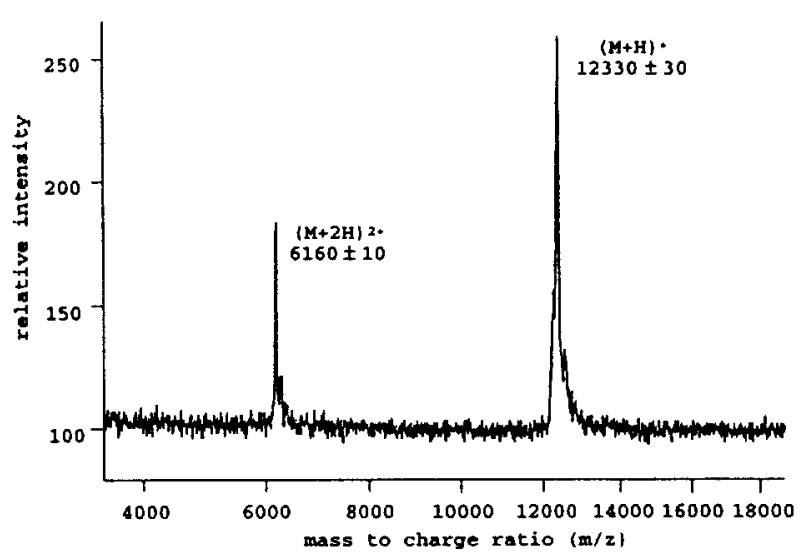

Figure 2. MALDI-TOF mass spectrum of cytochrome c sample.

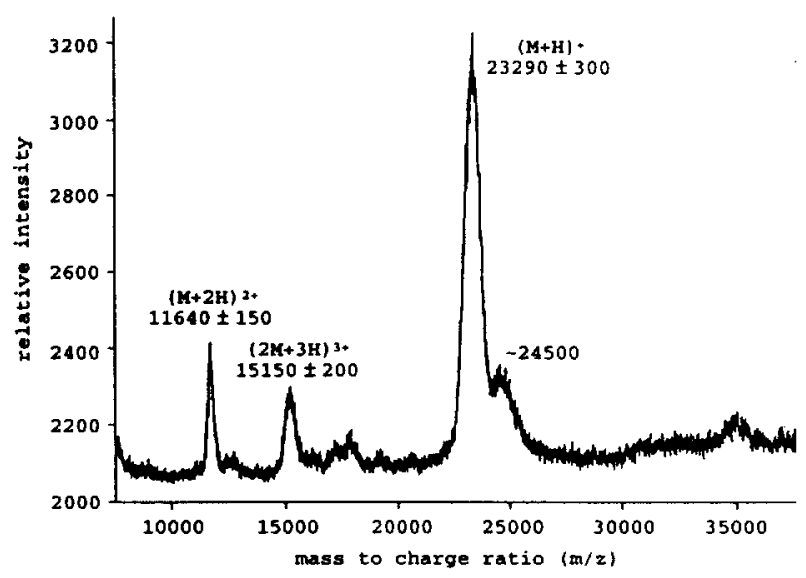

Figure 3. MALDI-TOF mass spectrum of bovine trypsin sample. 
Several unsuccessful attempts were made to record a mass spectrum for bovine albumin (molecular weight 66,267). It is likely that the bovine albumin samples, which were from a molecular weight marker kit for gel electrophoresis, contained significant quantities of sodium dodecyl sulfate (SDS). SDS is known to suppress the ion signal in MALDI-TOF/MS. ${ }^{6}$

\section{Future Work and Conclusions}

It should be possible to improve the mass resolution of the MALDI-TOF/MS by employing time-lag focusing. ${ }^{7}$ In this technique, the region between the sample holder and the first grid is kept field-free for a short time (roughly 0.3 to $3 \mu \mathrm{s}$ ) after the laser pulse, then the extraction field is rapidly applied. Resolution in the range 800 to 1000 has been demonstrated for proteins in a linear MALDI-TOF instrument, using time-lag focusing. ${ }^{8}$

A MALDI-TOF/MS system has been constructed from an existing instrument and spectra from peptides and proteins have been successfully acquired. The system currently allows sensitive detection of biomolecules with masses to at least $30 \mathrm{kDa}$. This system can be used as an analytical tool for BBRP programs, as well as for determining molecular weight distributions for polymers.

\section{References}

1. M. Karas and F. Hillenkamp, Anal. Chem. 60, 2299-2301 (1988).

2. F. Hillenkamp, M. Karas, R. C. Beavis, and B. T. Chait, Anal. Chem. 63, 1193A-1202A (1991).

3. M. George, J. M. Y. Wellemans, R. L. Cerny, M. L. Gross, K. Li, E. L. Cavalieri, J. Am. Soc. Mass Spectrom. 5, 1021-1025 (1994).

4. D. H. Russell, presented at the 42nd ASMS Conference on Mass Spectrometry and Allied Topics, May 29-June 3, 1994, Chicago, IL, p. 1.

5. R. C. Beavis and B. T. Chait, Anal. Chem. 62, 1836 (1990).

6. O. Vorm, B. T. Chait, and P. Roepstorff, 41st ASMS Conference Proceedings, 621a (1994).

7. W. C. Wiley and I. H. McLaren, Rev. Sci. Instrum. 26, 1150 (1955).

8. R. M. Whittal and L. Li, Anal. Chem. 67, 1950 (1995). 


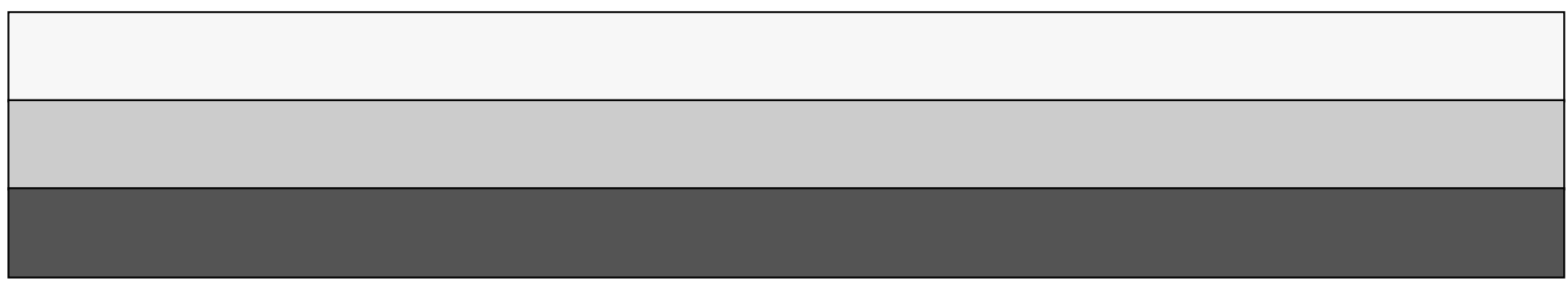

